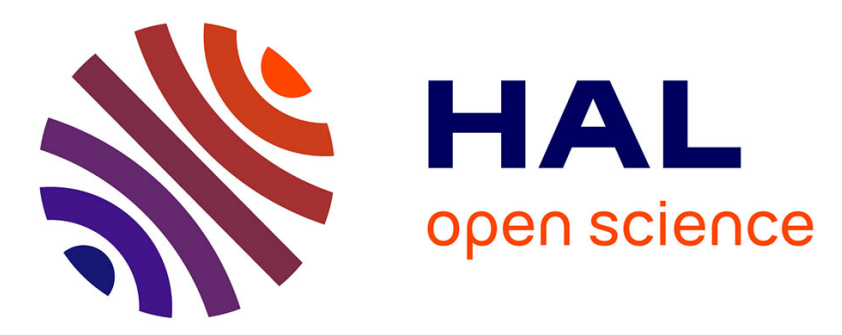

\title{
A micro-mechanical model for the plasticity of porous granular media and link with the Cam clay model
}

François Bignonnet, Luc Dormieux, Djimédo Kondo

\section{To cite this version:}

François Bignonnet, Luc Dormieux, Djimédo Kondo. A micro-mechanical model for the plasticity of porous granular media and link with the Cam clay model. International Journal of Plasticity, 2016, 79, pp.259-274. 10.1016/j.ijplas.2015.07.003 . hal-01337763

\section{HAL Id: hal-01337763 https://hal.science/hal-01337763}

Submitted on 27 Jun 2016

HAL is a multi-disciplinary open access archive for the deposit and dissemination of scientific research documents, whether they are published or not. The documents may come from teaching and research institutions in France or abroad, or from public or private research centers.
L'archive ouverte pluridisciplinaire HAL, est destinée au dépôt et à la diffusion de documents scientifiques de niveau recherche, publiés ou non, émanant des établissements d'enseignement et de recherche français ou étrangers, des laboratoires publics ou privés. 


\title{
A micro-mechanical model for the plasticity of porous granular media and link with the Cam clay model
}

\author{
François Bignonnet ${ }^{\mathrm{a}, \mathrm{b}, *}$, Luc Dormieux $^{\mathrm{b}}$, Djimédo Kondo ${ }^{\mathrm{c}}$ \\ ${ }^{a}$ École Centrale de Lille, Laboratoire de Mécanique de Lille (UMR 8107), F-59655 Villeneuve d'Ascq, France \\ ${ }^{b}$ Université Paris-Est, Laboratoire Navier (UMR 8205), CNRS, ENPC, IFSTTAR, F-77455 Marne-la-Vallée, France \\ ${ }^{c}$ Université Pierre et Marie Curie, UMR CNRS 7190, Institut Jean Le Rond d'Alembert, F-75252 Paris 05, France
}

\begin{abstract}
A micro-mechanical constitutive model for the plastic behavior of cohesive granular materials with hardening due to porosity changes is proposed. The plasticity model is based on a re-interpretation of a micromechanical strength model for cohesive frictional granular media. The hardening law by porosity changes explicitly stems from the homogenization process. The micro-macro plasticity model, analytical and fully explicit, depends only on two constant material parameters with a clear physical signification at the microscopic scale: the friction angle and the tensile strength of the grain to grain interfaces. The seminal ideas of critical state soil mechanics are retrieved: critical state line, state boundary surface in the stress/porosity space, hardening or softening due to change in porosity and ability to describe both dilatancy and contractancy. The established micro-mechanical model is very similar to the phenomenological modified Cam clay model, providing to the latter a microstructural based interpretation.
\end{abstract}

Keywords: ductility, microstructures, porous material, granular material, strengthening mechanisms

\section{Introduction}

Cohesive granular geo-materials (e.g. chalk, sandstone, clay) have applications in various engineering problems, such as underground waste/gas storage or unconventional gas production. Several propositions of constitutive modeling of their mechanical behavior have been formulated, and can be separated in two classes: phenomenological models based on experimental observations at the macroscopic scale and micromechanical models based on identified physical mechanisms at the microscopic scale.

Classical soil mechanics is based on the empirical approach. Experimental characterization of clays using shear or triaxial tests lead to the foundation of the critical state soil mechanics (Schofield and Wroth, 1968; Atkinson, 1993). According to these observations, upon loading of a granular soil, the voids ratio together with the stress state evolve until a critical state of voids ratio and stress is encountered. More precisely, the soil may be either contractant or dilatant depending on the position of the imposed load path with respect to the line of critical state (samples on the "wet side" or "dry side" of critical). These observations namely lead to the proposition of the celebrated Cam clay (Schofield and Wroth, 1968) and modified Cam clay (Roscoe and Burland, 1968) poro-plastic models. Subsequent modifications to these models have been proposed such as the "revised modified Cam clay" to account for strain hardening (Ami Saada et al., 1996), the "cemented Cam clay" to model the degradation of clay cementation (Nguyen et al., 2014) or a generalized Cam clay to include third-invariant effects (Perić and Ayari, 2002a,b); just to mention a few.

Once the critical state is reached, the stress state and the voids ratio no longer evolve but a free plastic flow of the material occurs. For materials whose solid phase keeps a constant volume, the plastic flow is then

\footnotetext{
*Corresponding author. Tel: +33 164153750

Email addresses: francois.bignonnet@enpc.fr (François Bignonnet), luc.dormieux@enpc.fr (Luc Dormieux), djimedo.kondo@upmc.fr (Djimédo Kondo)
} 
in pure shear strain. However, some materials such as the Tournemire shale (Masri et al., 2014) and the Callovo-Oxfordian argillite (Chiarelli et al., 2003) may exhibit dilatancy at the critical state, so that loose samples ("wet side" of critical) subjected to a triaxial test are contractant at first but then dilatant. This behavior may not be modeled by the modified Cam clay model in which the free plastic flow always occurs with no volumetric strain.

On the other hand, several authors have investigated the strength and plasticity of porous media using various multi-scale methods. Numerical studies of granular materials using Finite Element Method and Discrete Element Method have been carried out by Steinhauser and Grass (2005); Scholtès et al. (2010); Sibille et al. (2015). Alternatively, analytical homogenization methods based on the Hertz-Mindlin's model have been developed by Nicot et al. (2005); Scholtès et al. (2010); Zhu et al. (2010). Finally, an important contribution to the understanding of the behavior of porous and/or granular materials stems from continuum micromechanics. For example, Collard et al. (2010) have investigated the polycrystalline plasticity accounting for intra-granular slip bands by means of plastic heterogeneities. In a pioneering work, Gurson (1977) proposed a micromechanical strength model with an explicit dependence on the porosity of the material. Based on the same representation of the microstructure, the elasto-plastic response at large strain has then been studied (Barthélémy et al., 2003; Barthélémy, 2005). These studies proved that taking into account the porosity reduction during an hydrostatic compression leads to a hardening of this porous material.

Using Eshelby-based schemes and suitable non linear homogenization techniques (Suquet, 1995, 1997), a series of works (Barthélémy and Dormieux, 2004; Dormieux et al., 2007; Maghous et al., 2009; Maalej et al., 2009; Dormieux et al., 2010; Shen et al., 2012; He et al., 2013) has been devoted to the derivation of the strength of materials with various types of microstructures. The derived results have the advantage of explicitly depending on the microstructural parameters.

Some of these micromechanical strength models have also been reinterpreted as plasticity models. Xie and Shao (2006, 2012) modelled chalk plasticity based on a mixed criterion combining the criterion of Gurson (1977) for mostly hydrostatic loads and a modified Drucker-Prager criterion for mostly deviatoric loads. More recently, Xie and Shao (2015) proposed for chalk to use the approximate strength criterion of Guo et al. (2008). Similarly, Shen et al. (2012) proposed a plasticity model for Callovo-Oxfordian argillite based on a threescale micromechanical strength model. However, none of these models are purely based on micro-mechanics since they also involve the introduction of a phenomenological hardening law, taking the solid phase plastic deformation as a hardening variable. Moreover, phenomenological non associated plastic flow rules were needed in Shen et al. (2012); Xie and Shao $(2006,2012)$ to account for a transition from a contractant to a dilatant behavior during triaxial tests.

We propose a micromechanical model for the plasticity of granular material with the following main features. The model proposes a hardening or softening of the yield surface only due to porosity changes and not to stored elastic energy, without phenomenological hardening law. This purely micro-mechanical model retrieves the main features of critical state soil mechanics. Additionally, it allows to describe a transition from contractancy to dilatancy along a triaxial loading path as observed on Callovo-Oxfordian argillite or Tournemire shale, with an associated plastic flow rule stemming from the homogenization procedure. The scope of this paper is to propose a simple micro-mechanical interpretation to some classical critical state soil mechanics concepts as in the Cam clay model rather than a fully predictive model, which would require more sophisticated assumptions. The proposed plastic model is based on the micro-mechanical strength model derived by He et al. (2013), recalled in section 2. The micro-mechanical strength model is then carefully reinterpreted as a plasticity model in section 3. Finally, the micro-mechanical plasticity model is compared to classical soil mechanics observations together with the modified Cam clay model in section 4.

\section{The micro-mechanical strength model}

The main features of the micro-mechanical strength model for granular material proposed in He et al. (2013) are recalled in this section. 


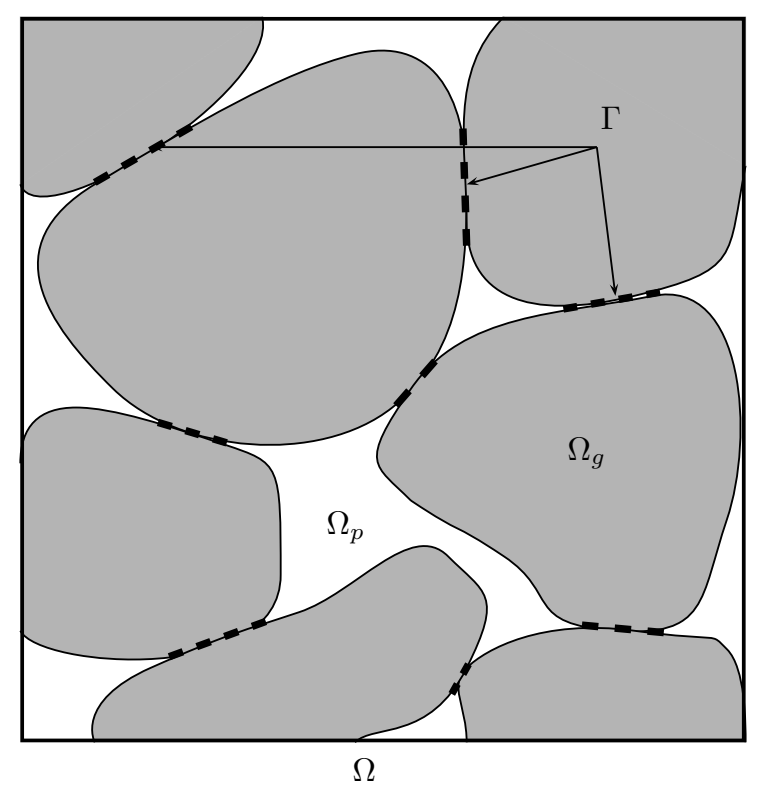

Figure 1: Description of the microstructure of the granular material.

\subsection{Morphological model}

At the microscopic scale, the granular material is described as a polycrystal of grains and pores (see Fig. 1). Its strength is controlled by the grain-to-grain interface properties, whereas the grains are assumed infinitely rigid.

A representative volume element (RVE) $\Omega$ of the microstructure of the granular material is considered. It comprises pores in the domain $\Omega_{p}$ and rigid grains in the domain $\Omega_{g}$ (see Fig. 1 ). The eulerian porosity of the granular material is defined as $\phi=\left|\Omega_{p}\right| /|\Omega|$ where $|\Omega|$ is the volume of the domain $\Omega$. The grains are in contact one with another through interfaces. The union of all the surfaces of the grain-to-grain interfaces of the RVE is denoted $\Gamma$. The specific surface of the grain-to-grain interfaces, which scales as the inverse of a length, is thus given by $|\Gamma| /|\Omega|$ where $|\Gamma|$ is the area of the surface $\Gamma$.

In the subsequent steps, the polycrystalline-like arrangement of the microstructure is accounted for in He et al. (2013) by resorting to the self-consistent scheme in the non-linear homogenization process, together with the solution to a generalized Eshelby solution (Hashin, 1991). In the generalized Eshelby problems, the pores and the rigid grains are assumed to be spherical. The radius of the rigid grains is denoted $r_{0}$. The specific surface of the grain-to-grain interfaces is then characterized by:

$$
\frac{|\Gamma|}{|\Omega|}=\frac{3 \lambda}{2 r_{0}}
$$

where the dimensionless parameter $\lambda$ is the product of the volume fraction of grains in the RVE by the fraction of the area of a grain which is in contact with other grains. Following Maalej et al. (2007), the parameter $\lambda$ may be estimated for the morphology at hand by :

$$
\lambda=(1-\phi)^{2}(1-2 \phi)
$$

\subsection{Strength properties of the microscopic constituents}

The grains are supposed infinitely rigid. The strength of the interfaces is described by an interface strength criterion $f_{\Gamma}$ to be met by the stress vector $\boldsymbol{T}$ acting on the interface. The interface strength criterion is supposed to be a cohesive frictional (or Mohr-Coulomb) criterion:

$$
f_{\Gamma}(\boldsymbol{T})=T_{t}+\alpha\left(T_{n}-h\right) \leqslant 0 \quad \text { with } \quad T_{n}=\boldsymbol{T} \cdot \boldsymbol{n} \quad ; \quad \boldsymbol{T}_{t}=\boldsymbol{T}-T_{n} \boldsymbol{n} \quad ; \quad T_{t}=\left|\boldsymbol{T}_{t}\right|
$$


where $\alpha$ denotes the coefficient of internal friction, $\alpha h$ is the cohesion and $\boldsymbol{n}$ is the unit vector normal to the interface. The quantity $h$ scales as a pressure and corresponds to the tensile strength of the interface.

\subsection{Homogenized strength properties}

\subsubsection{Dry case}

Using appropriate non linear homogenization techniques, He et al. (2013) recently derived the macroscopic strength of the granular medium in the $d r y$ case, i.e. when the pore pressure is null. Part of the strength homogenization procedure consists, for each loading direction, in the estimation of a failure mechanism, i.e. a velocity field defined in any point of the microstructure. In the framework of classical limit analysis, an associated flow rule is adopted in the interfaces:

$$
\llbracket v_{n} \rrbracket=\alpha \llbracket v_{t} \rrbracket \quad \text { with } \quad \llbracket v_{t} \rrbracket=\left|\llbracket \boldsymbol{v}_{t} \rrbracket\right|
$$

where $\llbracket \boldsymbol{v} \rrbracket$ denotes the velocity jump across the interface, $\llbracket v_{n} \rrbracket=\llbracket \boldsymbol{v} \rrbracket \cdot \boldsymbol{n}$ its normal component and $\llbracket \boldsymbol{v}_{t} \rrbracket=$ $\llbracket \boldsymbol{v} \rrbracket-\llbracket v_{n} \rrbracket \boldsymbol{n}$ the tangential velocity jump. In what follows, we will refer to localization of the failure mechanism as the process of extracting information from the velocity field of the failure mechanism, such as the average of $\llbracket v_{n} \rrbracket$ over all interfaces or the variation pore volume.

The homogenized strength criterion of the dry granular material is controlled by the porosity. The boundary $\partial G$ of the homogenized strength domain $G$ derived in He et al. (2013) for the admissible macroscopic stress states $\boldsymbol{\sigma}$ is a conic in the $\left(\sigma_{m}, \sigma_{d}\right)$ plane (see Fig. 2) where

$$
\sigma_{m}=\frac{1}{3} \operatorname{tr}(\boldsymbol{\sigma}) \quad ; \quad \boldsymbol{\sigma}_{d}=\boldsymbol{\sigma}-\sigma_{m} \mathbf{1} \quad ; \quad \sigma_{d}=\sqrt{\boldsymbol{\sigma}_{d}: \boldsymbol{\sigma}_{d}} .
$$

are the two first stress invariants referred to as the mean stress $\sigma_{m}$ and the deviatoric stress $\sigma_{d}$.

The derived results are expressed as a function of the following expressions which arise from the homogenization work-flow :

$$
\mathcal{M}=\frac{1-2 \phi}{3 \phi-1} \quad ; \quad \mathcal{K}=4 \mathcal{M} \frac{1-\phi}{3 \phi} .
$$

The case $1 / 3<\phi<1 / 2$. :

The type of the conic which describes the boundary $\partial G$ of the macroscopic strength domain is controlled by the dimensionless parameter $\delta$ defined as:

$$
\delta=\frac{3 \alpha^{2} \mathcal{K}}{2 \lambda} .
$$

- case $\delta<1$ :

The boundary $\partial G$ of the macroscopic strength criterion is an ellipse in the $\left(\sigma_{m}, \sigma_{d}\right)$ plane, centered at $(-c, 0)$, with semi-axes $\sqrt{a}$ and $\sqrt{b}$ (see Fig. 2) and can be described by the strength criterion $f$ :

$$
f(\boldsymbol{\sigma}, p=0, \phi)=\frac{\left(\sigma_{m}+c\right)^{2}}{a}+\frac{\sigma_{d}^{2}}{b}-1 \leq 0
$$

where the parameters $a, b$ and $c$ are the functions of $\phi$ given by:

$$
a(\phi)=\left(\frac{h \lambda}{1-\delta}\right)^{2} \delta \quad ; \quad b(\phi)=(h \lambda)^{2} \frac{2 \delta \mathcal{M}}{(1-\delta) \mathcal{K}} \quad ; \quad c(\phi)=h \lambda \frac{\delta}{1-\delta}
$$

- case $\delta>1$ :

The boundary $\partial G$ of the macroscopic strength criterion is a hyperbola in the $\left(\sigma_{m}, \sigma_{d}\right)$ plane (see Fig. 2) which can be described by the strength criterion:

$$
f(\boldsymbol{\sigma}, p=0, \phi)=\frac{\left(\sigma_{m}+c\right)^{2}}{a}-\frac{\sigma_{d}^{2}}{b}-1 \leq 0
$$

with $a, b$ and $c$ are given by (9). In this case, $-c$ is the isotropic tensile strength. Asymptotically at high confining stress, the criterion (10) tends towards a Drucker-Prager criterion. 
- case $\delta=1$ :

The boundary $\partial G$ of the macroscopic strength criterion is a parabola in the $\left(\sigma_{m}, \sigma_{d}\right)$ plane (see Fig. 2) which can be described by the strength criterion:

$$
f_{m}(\boldsymbol{\sigma}, p=0, \phi)=\frac{\sigma_{m}}{a^{\prime}}+\frac{\sigma_{d}^{2}}{b^{\prime}}-1 \leq 0 \quad \text { with } \quad a^{\prime}=\frac{h \lambda}{2} \quad ; \quad b^{\prime}=\frac{(h \lambda)^{2} 2 \delta \mathcal{M}}{\mathcal{K}}
$$

For a given value of the internal friction coefficient $\alpha$, the transition from an elliptic to an hyperbolic strength criterion occurs for a transitional porosity value $\phi^{\text {trans }}$ such that $\delta=1$. If $\phi>\phi^{\text {trans }}$ then $\delta<1$ and the criterion is elliptic ; if $\phi<\phi^{\text {trans }}$ then $\delta>1$ and the criterion is hyperbolic. Using the relation (2), the transitional porosity is the solution to:

$$
\phi^{\text {trans }}\left(1-\phi^{\text {trans }}\right)\left(3 \phi^{\text {trans }}-1\right)=2 \alpha^{2} \text {. }
$$

Porosities greater than $1 / 3$ are encountered in several types of geomaterials. The Haubourdin chalk exhibits porosities ranging from 40 to $45 \%$ (Nadah et al., 2013). The Callovo-Oxfordian argillite, made of a clay matrix and more than $50 \%$ of non porous calcite and quartz, has a macroscopic porosity in the range $14-22 \%$. However, the mesoscopic porosity of its clay matrix is comprised between 35 and 40\% (Song et al., 2015). Using the strength homogenization procedure presented in Bignonnet et al. (2015), the macroscopic strength of the argillite could therefore be described by an elliptic criterion, even though its apparent macroscopic porosity is less than $1 / 3$.

The case $0<\phi<1 / 3$. :

The macroscopic strength criterion is then simply given by:

$$
f(\boldsymbol{\sigma}, p=0, \phi)=\sigma_{m}-\lambda h \leq 0
$$

This particular shape of the strength criterion results from the strong assumption at the microscopic scale that the grains are infinitely rigid and that the inter-granular failure is the predominant mechanism. Clearly, the multi-scale modelling of the strength of low porosity granular materials would require the proposal of intra-granular failure mechanisms, but is beyond the scope of the present paper.

Further, the cut-off values $\phi=1 / 3$ and $\phi=1 / 2$ are to be considered as indicative only. They indeed come from the use of a spherical representation of the grains and pores in the self-consistent homogenization scheme, but would likely depend on the grain morphology for actual materials.

It is noteworthy that this macroscopic strength criterion derived by He et al. (2013) using homogenization techniques exhibits such a diversity of shapes (see Fig. 2) for a very restricted number of microscopic physical parameters: the porosity $\phi$, the interface tensile strength $h$ and the interface internal friction coefficient $\alpha$.

A particularly interesting feature of the macroscopic strength criterion lies in the fact that, for porosity values slightly greater than $\phi^{\text {trans }}$ (defined in (12)), the elliptic criterion (8) is very sensitive to porosity changes (see e.g. Fig. 3).

\subsubsection{Saturated case}

We now consider the case where the pore space is filled with a fluid with uniform pore pressure $p$. The homogenization process presented in He et al. (2013) in the $d r y$ case can be readily adapted to derive the strength of the saturated granular medium. Under the assumption that the interface criterion is not modified by pore pressure, the resulting strength criterion exhibits an effective stress $\tilde{\boldsymbol{\sigma}}$ defined as

$$
\tilde{\boldsymbol{\sigma}}=\frac{\boldsymbol{\sigma}+p \mathbf{1}}{1+p / h}
$$

Note that this effective stress is the same as the effective stress obtained by de Buhan and Dormieux (1996) in the case of a porous material with a uniform solid phase whose strength is governed by a Mohr-Coulomb or Drucker-Prager criterion. This implies that the criterion in the saturated case can be deduced from the dry case by:

$$
f(\boldsymbol{\sigma}, p, \phi)=f(\tilde{\boldsymbol{\sigma}}, 0, \phi)
$$




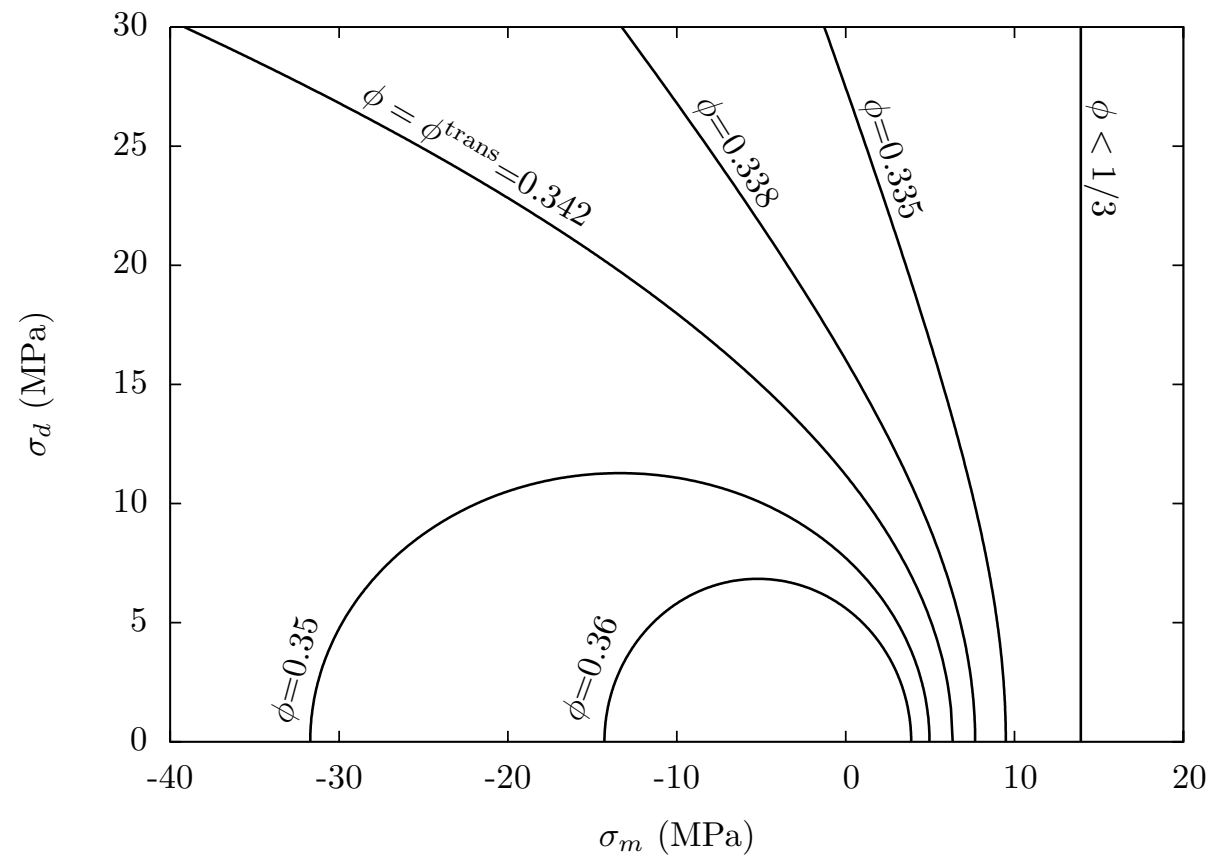

Figure 2: Evolution with porosity $\phi$ of the macroscopic strength criterion in the dry case for $h=93 \mathrm{MPa}$ and $\alpha=0.055$ (hence $\phi^{\text {trans }} \approx 0.342$ from (12)) . The criterion is: elliptic (8) for $\phi^{\text {trans }}<\phi<1 / 2$, parabolic (11) for $\phi=\phi^{\text {trans }}$, hyperbolic (10) for $1 / 3<\phi<\phi^{\text {trans }}$ or a limit (13) on the isotropic traction for $0<\phi<1 / 3$.

\section{The micro-mechanical poro-plastic model}

\subsection{Thought model}

The strength model presented in section 2 allows to predict, under the assumption of ductility of the micro-constituents, the macroscopic stress which leads to failure of the granular medium.

The purpose of this paper is to propose a reinterpretation of the strength model into an elasto-plastic model. To avoid possible confusions, let us precise some terminology. As a toy example, so as to illustrate the concepts, we will consider a simplified microstructure of a porous media: an elasto-plastic hollow sphere. Just as in the model of Gurson (1977), this composite sphere comprises a spherical shell made up of an elasto-plastic material obeying a Von Mises plasticity criterion, and a spherical void in its center. The external surface of the hollow sphere is subjected to an external pressure. This load can be considered as a macroscopic stress for the simple microstructure.

At first, assume geometry changes due to loading are infinitesimal and may be neglected. The strength of the hollow sphere is characterized by the maximum macroscopic stress that can be applied before failure. The strength can be obtained by means of limit analysis methods. In elasto-plasticity, a distinction must be made between the elastic limit (or yield stress) and the ultimate stress. The elastic limit of the microstructure is the maximal macroscopic stress that can be applied while the evolution at any point of the microstructure remains elastic (i.e. before plasticity occurs). As the macroscopic stress is further increased, part of the microstructure undergoes plastic strains. This step corresponds to a constrained plastic flow. In the hollow sphere example, if $p_{e}$ is the pressure corresponding to the elastic limit, applying a pressure $p>p_{e}$ leads to the propagation of a plastified shell from the inner wall of the hollow sphere. If the pressure is further increased to the value $p_{f}$ for which the plastified shell reaches the external wall of the hollow sphere, the microstructure undergoes free plastic flow. The pressure $p_{f}$ corresponds the ultimate macroscopic stress.

A general theorem of limit analysis states that the failure limit of a structure for given local strength criteria is the same as the ultimate stress for the structure with equivalent plastic criteria and associated 
flow rule.

Note that in the hollow sphere example, if the pressure is first set to a value $p^{\prime}$ between the initial elastic limit and the ultimate stress, and then removed, the new elastic limit will be $p^{\prime}$ for subsequent loading. This corresponds to a hardening of the hollow sphere considered as a toy example of a porous media. More precisely, this type of hardening is a hardening due to stored elastic energy. The stored elastic energy, which cannot be retrieved, corresponds to the elastic strains in the plastified shell needed to meet geometric compatibility conditions in the unloaded state.

There may also be a second type of hardening. We now assume the geometry changes of the microstructure can not be neglected as the free plastic flow occurs. As a consequence, the porosity of the hollow sphere decreases with increasing external pressure. Therefore loads greater than the initial ultimate pressure $p_{f}$ may be applied (see Barthélémy et al. (2003)). This corresponds to a hardening due to geometry changes. In the present paper, we precisely intend to take advantage of the following remark in Barthélémy et al. (2003) for the hollow sphere, and to transpose it to the case of the granular material:

the pressure, which is applied to the sphere in the domain of free plastic flow, can be interpreted as the "limit load" in the sense of the theory of limit analysis but for the current value of the eulerian porosity $\phi$, that is, for the current geometry. Hence, if geometry changes are taken into account through an update of $\phi$, the compaction curve in the domain of free plastic flow can be determined from the theory of limit analysis. This, of course, requires to use the relationship between $\phi$ and a macroscopic strain parameter.

Unlike the case of the hollow sphere for which large porosity changes are required to obtain a hardening by geometry change, we expect the high sensitivity of the strength criterion proposed by He et al. (2013) to porosities $\phi$ around the transition value (12) to ensure a sizeable hardening for a very small change in porosity, as commonly observed for granular materials (Atkinson, 1993). This is a direct consequence of the fact that the morphological model used in He et al. (2013) is more representative of a porous granular media than the hollow sphere.

Due to the great sensitivity to the eulerian porosity of the criterion proposed by He et al. (2013) for granular media, we will assume in the following developments that the hardening due to stored energy can be neglected relative to the hardening due to geometry changes.

From an energetical point of view, this amounts to stating that in an elasto-plastic evolution of the microstructure, the rate of change of the stored energy $\mathcal{U}$ can be neglected relative to the poro-plastic power $\mathcal{P}^{p}$ in the intrinsic power dissipation $\mathcal{D}$ defined as (Coussy, 1991):

$$
\mathcal{D}=\mathcal{P}^{p}-\dot{\mathcal{U}} \geq 0 \quad \text { with } \quad \mathcal{P}^{p}=\boldsymbol{\sigma}: \boldsymbol{d}^{p}+p \dot{\Phi^{p}}
$$

where $\boldsymbol{d}^{p}$ is the macroscopic plastic strain rates, $\boldsymbol{\sigma}$ the macroscopic stress, $p$ the pore pressure and $\Phi^{p}$ the plastic porosity which is a lagrangian quantity. If all of the pore volume change is irreversible between time $t$ and $t+\mathrm{d} t$, the rate of variation of the lagrangian plastic porosity defined on the reference configuration at time $t$ is related to the change in pore volume $\left|\Omega_{p}\right|$ of the RVE by:

$$
\dot{\Phi^{p}}=\lim _{\mathrm{d} t \rightarrow 0} \frac{\left|\Omega_{p}(t+\mathrm{d} t)\right|-\left|\Omega_{p}(t)\right|}{|\Omega(t)| \mathrm{d} t}
$$

From a thermo-dynamical point of view, the intrinsic power dissipation $\mathcal{D}$ in (16) must be positive (Coussy, 1991). If the rate of change of the stored energy $\dot{\mathcal{U}}$ is neglected, the poro-plastic power $\mathcal{P}^{p}$ must be positive.

To sum up, the present paper aims at proposing a micro-mechanical model, based on rigorous homogenization techniques, to help for a micro-structural interpretation to the hardening classically observed on porous granular media. We do not intend to put forward a new type of hardening at the macroscopic scale.

The following developments focus on the case where the plastic criterion of the granular medium is elliptic (i.e. $\phi>\phi^{\text {trans }}$ defined in (12)), with a yield surface described by (8). 


\subsection{Macroscopic plastic flow rule}

To start with, we check that the homogenization process preserves the associated character of the plastic flow rule. In other words, does the assumption of a normality rule for the plasticity of the grain-to-grain interfaces at the microscopic scale implies a normality rule for the macroscopic plasticity criterion?

To answer this, we will turn to the localization of the failure mechanism of the microstructure proposed by He et al. (2013). By construction, it is readily seen that the normal flow rule is fulfilled for the strain rates. Hence, only the normality of the flow rule for porosity evolution has to be checked.

\subsubsection{The macroscopic flow rule under the assumption of associated plasticity}

Under the assumption that the normality rule is fulfilled for the flow rule at the macroscopic scale, the plastic strain rates and the irreversible change in pore volume between time $t$ and $t+\mathrm{d} t$ normalized by the volume of the RVE at $t$ should be given by the normality rule (Coussy, 1991):

$$
\boldsymbol{d}^{p}=\dot{\Lambda} \frac{\partial f(\boldsymbol{\sigma}, p, \phi)}{\partial \boldsymbol{\sigma}} \quad ; \quad \dot{\Phi}^{p}=\dot{\Lambda} \frac{\partial f(\boldsymbol{\sigma}, p, \phi)}{\partial p}
$$

where the plastic multiplier $\dot{\Lambda} \geq 0$ and, if all of the pore volume change is irreversible, $\dot{\Phi}^{p}$ is the rate of variation of the lagrangian porosity $\Phi$ defined on the configuration at time $t$ which is expressed by (17). The later is not to be confused with

$$
\dot{\phi}=\lim _{\mathrm{d} t \rightarrow 0} \frac{1}{\mathrm{~d} t}\left(\frac{\left|\Omega_{p}(t+\mathrm{d} t)\right|}{|\Omega(t+\mathrm{d} t)|}-\frac{\left|\Omega_{p}(t)\right|}{|\Omega(t)|}\right)
$$

which is the rate of variation of the eulerian porosity $\phi$. If all of the volume change of the RVE is irreversible, the two are readily related by

$$
\dot{\Phi^{p}}=\dot{\phi}+\phi d_{v}^{p},
$$

where $d_{v}^{p}$ (resp. $d_{d}^{p}$ ) is the volumetric (resp. deviatoric) plastic strain rates defined by:

$$
d_{v}^{p}=\operatorname{tr}\left(\boldsymbol{d}^{p}\right) \quad ; \quad \boldsymbol{d}_{d}^{p}=\boldsymbol{d}^{p}-\frac{1}{3} d_{v}^{p} \mathbf{1} \quad ; \quad d_{d}^{p}=\sqrt{\boldsymbol{d}_{d}^{p}: \boldsymbol{d}_{d}^{p}} .
$$

The normality rule, if met, implies that the poro-plastic power $\mathcal{P}^{p}$ in (16) is positive. Hence, if the stored energy $\mathcal{U}$ is neglected, the normality rule ensures the positivity of the intrinsic dissipation $\mathcal{D}$ in (16).

Combining the two flow rules in (18), the change in pore volume must be related to the volumetric strain rates by

$$
\dot{\Phi}^{p}=\frac{\partial f}{\partial p}\left(\frac{\partial f}{\partial \sigma_{m}}\right)^{-1} d_{v}^{p}=\frac{1}{h}\left(h+c-\frac{a}{\tilde{\sigma}_{m}+c}\right) d_{v}^{p}
$$

if the normal flow rule is met. Note that the expressions (18) to (22) hold in the dry case, when $p=0$. In this case, the partial derivative with respect to $p$ involved in (18) has of course to be computed prior to setting $p=0$ and is not null.

\subsubsection{Proof that the porosity flow rule is associated}

Let us now show that the normality of the porosity flow rule is indeed fulfilled. To do so, we will proceed to the localization of the failure mechanism (using the terminology introduced in Sec. 2.3.1) of the microstructure proposed by He et al. (2013).

First, the average of the volume change over the microscopic scale indicates that it results from the competition between pore volume change and interface dilatation:

$$
d_{v}^{p}=\dot{\Phi}^{p}+\frac{|\Gamma|}{|\Omega|} \overline{\llbracket v_{n} \rrbracket} \rrbracket^{\Gamma}
$$




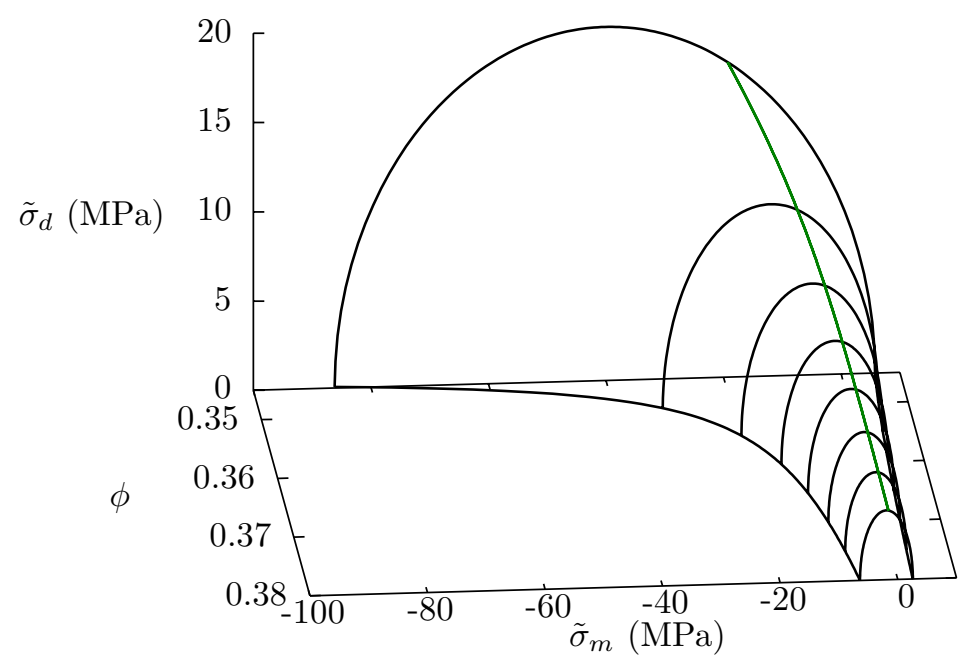

Figure 3: The boundary state surface (8) of the micro-mechanical poro-plastic model for $h=93 \mathrm{MPa}$ and $\alpha=0.055$. The green line is the critical state line (29).

Second, for the stress state $\boldsymbol{\sigma}$ on the boundary of $G_{m}$ whose normal is oriented by $\boldsymbol{d}^{p}$, the average of the normal velocity jump across the interfaces as localized by He et al. (2013) is given by

$$
{\overline{\llbracket v_{n} \rrbracket}}^{\Gamma}(\boldsymbol{\sigma}, p, \phi)=\frac{|\Omega|}{|\Gamma|} v(\tilde{\boldsymbol{\sigma}}, \phi) d_{v}^{p}
$$

with

$$
v(\tilde{\boldsymbol{\sigma}}, \phi)=\frac{1}{h}\left(\frac{a(\phi)}{\tilde{\sigma}_{m}+c(\phi)}-c(\phi)\right)
$$

Accordingly, the pore volume change found by localization of the failure mechanism is

$$
\dot{\Phi}^{p}=(1-v(\tilde{\boldsymbol{\sigma}}, \phi)) d_{v}^{p}=\frac{1}{h}\left(h+c(\phi)-\frac{a(\phi)}{\tilde{\sigma}_{m}+c(\phi)}\right) d_{v}^{p}
$$

which is identical to the result (22) derived under the assumption normality of the macroscopic flow rule. Thus, the homogenization method is consistent for the flow rule. In the case of a Tresca interface (i.e. in the limit case where the friction angle $\alpha \rightarrow 0$ with $h \alpha$ constant), the relation (26) simplifies to the classical relation $\dot{\Phi}^{p}=d_{v}^{p}$ since there is no interface dilatation term and the grains are incompressible.

Moreover, it appears that the effective stress for strength properties $\tilde{\boldsymbol{\sigma}}$ is also an effective stress for the plasticity criterion as well as for the plastic flow rule. This particular feature results from the fact that the stored energy has been neglected.

\subsection{Hardening or softening due to porosity changes}

The plastic criterion (8) is highly sensible to porosity changes. We propose to take advantage of this feature to propose a hardening (or softening) law. The law will be derived by localization of the porosity changes based on the micromechanical model. The eulerian porosity is taken as a hardening variable. We recall that the proposed hardening is due to geometry changes and not to stored elastic energy.

As seen previously, the eulerian porosity change is related to the plastic volumetric strain by

$$
\dot{\phi}=\dot{\Phi^{p}}-\phi d_{v}^{p}=(1-\phi-v(\tilde{\boldsymbol{\sigma}}, \phi)) d_{v}^{p}
$$


As the porosity is the only hardening variable, it is particularly interesting to seek the stress/pressure/porosity states for which $\dot{\phi}$ cancels. These states are so-called critical states since when they are reached, the elastic limit no longer evolves and free plastic flow of the material occurs.

According to the macroscopic normal flow rule, we notice that

$$
\frac{d_{v}^{p}}{d_{d}^{p}}=\frac{b\left(\tilde{\sigma}_{m}+c\right)}{a \tilde{\sigma}_{d}}
$$

Hence, the volumetric strain rate $d_{v}^{p}$ cancels when $\tilde{\sigma}_{m}=-c$ (and $\tilde{\sigma}_{d}=\sqrt{b}$ ), and the porosity evolution is strictly negative since $\dot{\phi} \rightarrow-\sqrt{b} d_{d}^{p} / h$. The critical state is thus only reached when $1-\phi-v(\tilde{\boldsymbol{\sigma}}, \phi)=0$, that is when

$$
\tilde{\sigma}_{m}^{\text {crit. }}=\frac{a}{c+h(1-\phi)}-c \quad ; \quad \tilde{\sigma}_{d}^{\text {crit. }}=\sqrt{b\left(1-\frac{a}{[c+h(1-\phi)]^{2}}\right)}
$$

The parametric equation (29) hence defines a critical state line which is illustrated Figs. 3 and 4 a.

\section{Comparison to classical soil mechanics}

The micro-mechanical model is compared to the modified Cam clay model and to classical experimental observations in soil mechanics.

\subsection{The modified Cam clay model}

First, the similarity to the empirical modified Cam clay (MCC) model (Roscoe and Burland, 1968) is striking. The yield surface of the MCC poro-plastic model is an ellipse crossing the origin in the $\left(\sigma_{m}, \sigma_{d}\right)$ plane (see Fig. $4 \mathrm{~b}$ ) defined by the criterion $f_{\mathrm{MCC}}$ :

$$
f_{\mathrm{MCC}}(\boldsymbol{\sigma}, p)=\left(\sigma_{m}^{\prime}+P_{\mathrm{c}}\right) \sigma_{m}^{\prime}+\frac{3 \sigma_{d}^{\prime 2}}{2 M^{2}} \leq 0
$$

where $\boldsymbol{\sigma}^{\prime}$ is a plastic effective stress for the MCC model which corresponds to the Terzaghi effective stress:

$$
\boldsymbol{\sigma}^{\prime}=\boldsymbol{\sigma}+p \mathbf{1}
$$

The two parameters in (30) are the pre-consolidation pressure $P_{\mathrm{c}}$ which is the isotropic compressive yield stress and a constant $M$ which is related to the aspect ratio of the ellipse.

The plastic flow rule is associated and the normality rule of the MCC model can be explicited as:

$$
\boldsymbol{d}^{p}=\dot{\Lambda}\left[\left(2 \sigma_{m}^{\prime}+P_{\mathrm{c}}\right) \frac{\mathbf{1}}{3}+\frac{3}{M^{2}} \boldsymbol{\sigma}_{d}^{\prime}\right] \quad ; \quad \dot{\Phi}^{p}=\dot{\Lambda}\left(2 \sigma_{m}^{\prime}+P_{\mathrm{c}}\right)=d_{v}^{p}
$$

The combination of the two flow rules indicates that the porosity changes are proportional to the volumetric strain rates. If the total volumetric strain rate is approximately equal to the plastic volumetric strain rate, the volume change averaging rule then implies:

$$
\dot{\Phi}^{p}=d_{v}^{p} \Rightarrow \dot{\phi}=(1-\phi) d_{v}^{p}
$$

The relation (33) which is due to the incompressibility of the solid phase is the same as in the Gurson model and as (27) in the particular case of the Tresca interfaces (no interface dilatation). It implies that the critical state is always reached at the top of the ellipses in the $\left(\sigma_{m}^{\prime}, \sigma_{d}^{\prime}\right)$ plane for the MCC model. The parameter $M$ is then the slope of the critical state line in the $\left(\sigma_{m}^{\prime}, \sigma_{\text {eq }}^{\prime}\right)$ plane where $\sigma_{\text {eq }}^{\prime}=\sqrt{3 / 2} \sigma_{d}^{\prime}$ is the Von Mises equivalent effective stress (see Fig. 4b). 


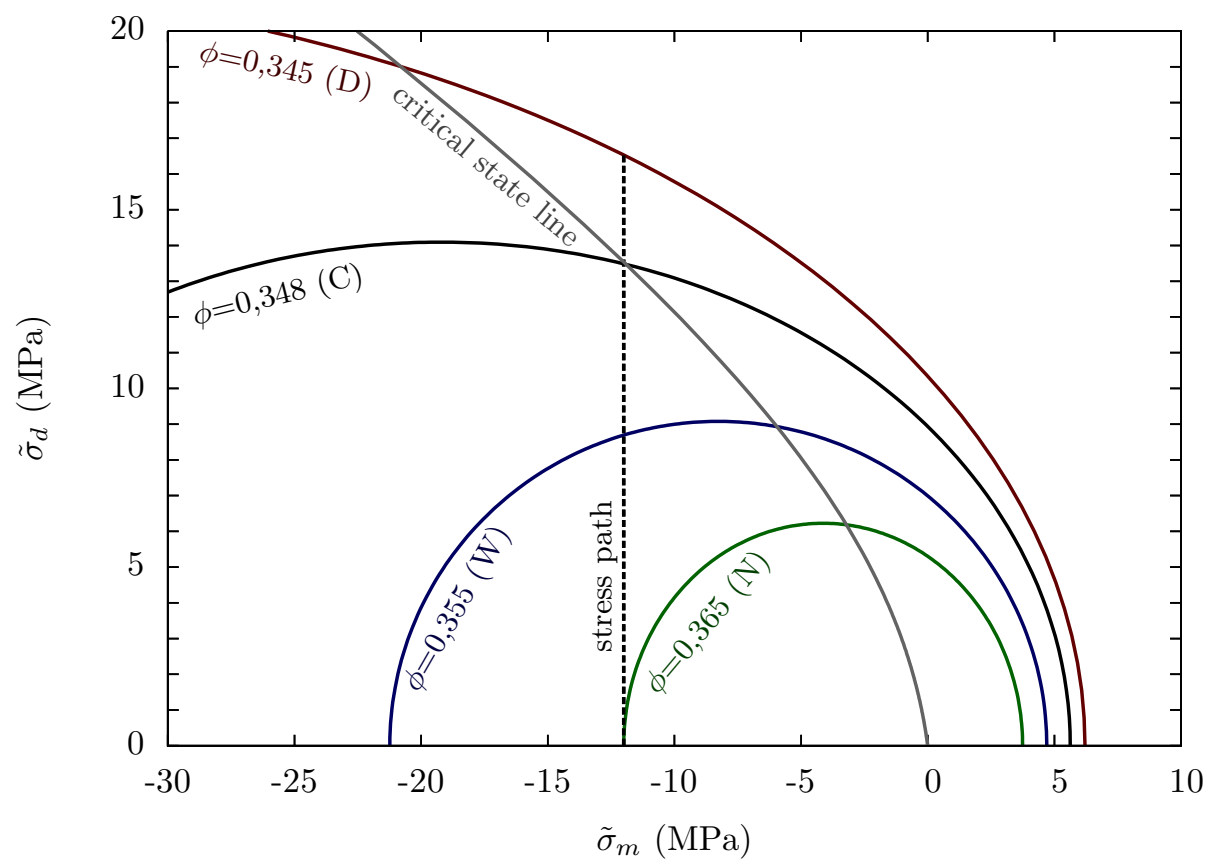

(a) micro-mechanical model

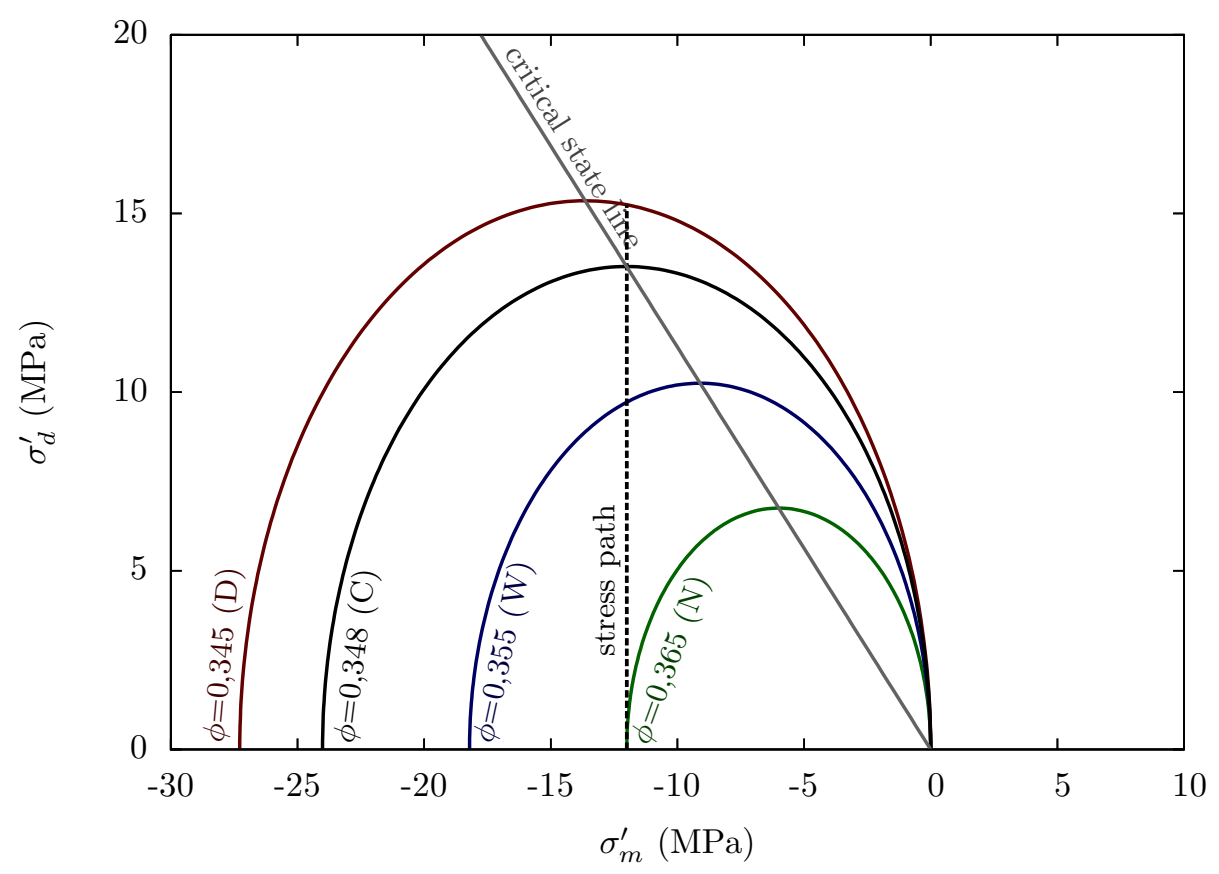

(b) modified Cam clay model

Figure 4: Projection in the $\left(\Sigma_{m}, \Sigma_{d}\right)$ plane of the state boundary surface and the critical state line for the micro-mechanical and MCC models for different porosities with the model parameters of Tab. 1 . Chosen porosities correspond to the initial and final yield surfaces for the three situations of simulations presented Fig. 6 (right) : $\mathrm{N}=$ "normally consolidated", $\mathrm{W}=$ "wet side of critical", $\mathrm{D}=$ "dry side of critical", $\mathrm{C}=$ critical state (final state). 


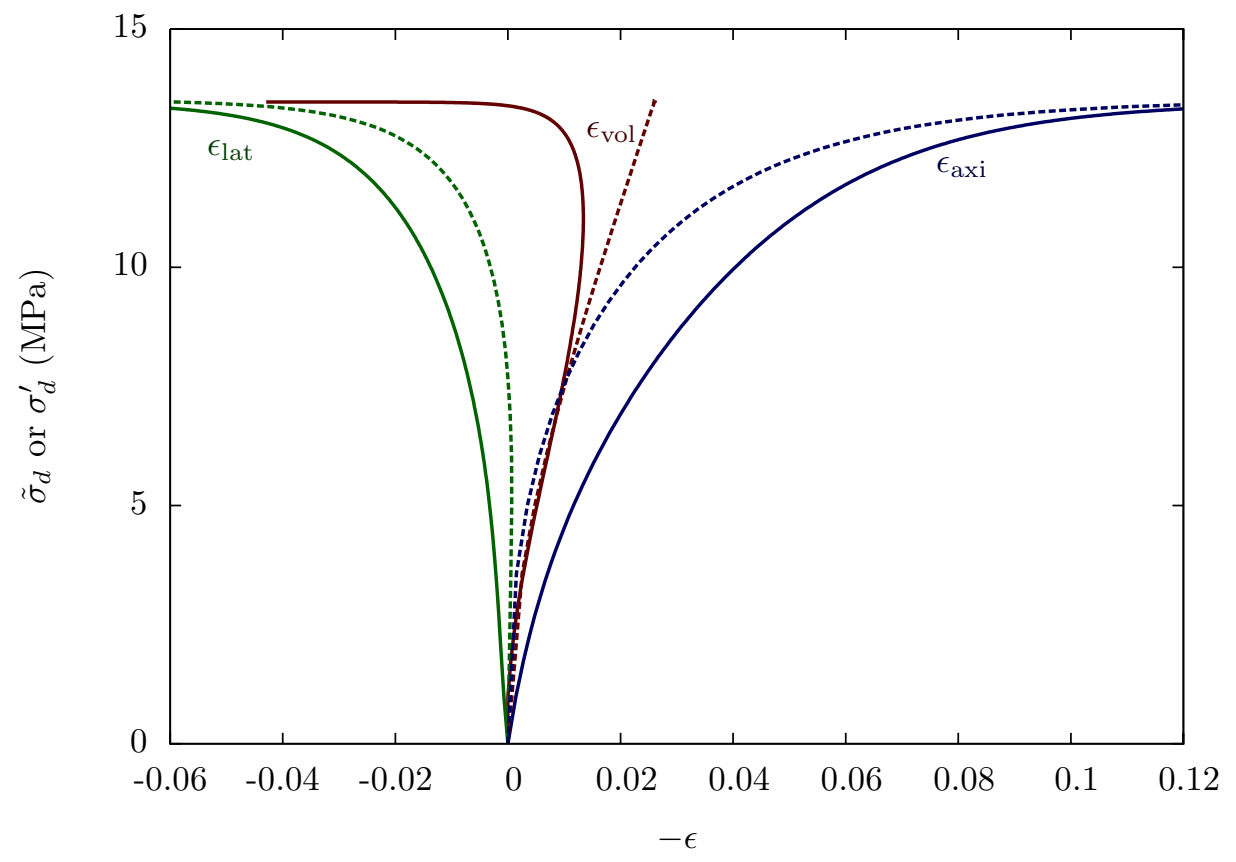

Figure 5: Simulation using the micro-mechanical (full line) and modified Cam clay (dashed line) models of the axial, lateral and volumetric strains for a triaxial test with constant mean stress with the model parameters of Tab. 1 . The imposed mean stress is equal to the initial pre-consolidation pressure, which corresponds to the "normally consolidated" situation.

In the MCC model, the pre-consolidation pressure $P_{\mathrm{c}}$ is related to the voids ratio by an isotropic compression or swelling law, the so-called normal compression line :

$$
P_{\mathrm{c}}(e)=P_{\mathrm{c}}^{0} \exp \left(-\kappa\left(e-e^{0}\right)\right) \quad \text { with } \quad e=\frac{\phi}{1-\phi}
$$

where $\kappa$ is the inverse of the virgin compression index, $e^{0}$ is a reference voids ratio and $P_{\mathrm{c}}^{0}$ the corresponding reference pre-consolidation pressure. Note that for the micro-mechanical model a normal compression line analogous to (34) exists since the pre-consolidation pressure is $\sqrt{a(\phi)}+c(\phi)$ with $a$ and $c$ defined in (9).

The law corresponding to the normal compression line allows to construct a state boundary surface of the effective stress and porosity states which correspond to yield. The relation (34) corresponds to a hardening law due to porosity changes.

There are thus three independent constant material parameters in the MCC model: the pre-consolidation pressure $P_{\mathrm{c}}^{0}$ at reference voids ratio $e^{0}$ and the inverse of the virgin compression index $\kappa$ which carry information of the normal compression line, as well as the ratio $M$ which corresponds to the slope of the critical state line in the mean stress - Von Mises equivalent stress plane.

To sum up, the modified Cam-Clay model and the micro-mechanical model presented in this paper present the following similarities:

- The yield surface is an ellipse in the $\left(\Sigma_{m}, \Sigma_{d}\right)$ plane with explicit dependence on the porosity $\phi$. This leads to the definition of a state boundary surface in the $\left(\Sigma_{m}, \Sigma_{d}, \phi\right)$ space.

- An effective plastic stress can be defined to account for a total saturation of the pore space.

- The flow rule is associated for plastic strains rates and plastic porosity variation. 
- Hardening or softening results from porosity changes.

- A critical state line corresponding to final stress and porosity states can be defined.

- Depending on the position of the load path with respect to the critical state line, the behavior may be dilatant and/or contractant.

Let us now underline the main differences between the two models:

- The isotropic tensile strength is null in the MCC model but strictly positive in the micro-mechanical model. However, recently proposed extensions to the MCC model also have a positive tensile strength (Suebsuk et al., 2010; Nguyen et al., 2014).

- The pre-consolidation pressure diverges to infinity for $\phi=\phi^{\text {trans }}$ given by (12) in the micro-mechanical model, whereas it remains always finite in the MCC model.

- The aspect ratio of the ellipses defining the yield surface depends on the porosity $\phi$ in the micromechanical model, whereas it is constant in the MCC model.

- The critical stress state is at the top of the ellipses in the MCC model, so that the free plastic flow of the material is without volumetric strain. On the contrary, the critical stress state is on the tensile side of the yield surface in the micro-mechanical model, resulting in a free plastic flow of the microstructure which is always dilatant. The origin of the dilatancy is clearly identified at the microscopic scale : it is due to the dilatancy of the Mohr-Coulomb interfaces with associated flow rule.

- The plastic effective stress (31) is linear in the pore pressure $p$ for the MCC model, but non linear (see (14)) in the micro-mechanical model.

\subsection{Simulations of triaxial tests at constant mean stress and comparison to experiments}

The micro-mechanical model and the MCC models are now used to simulate triaxial tests. A specific case of triaxial test is considered: a sample is first subjected to an hydrostatic confining pressure. From this first state, an additional axial compression is applied while the lateral pressure is lowered so as to keep the mean stress constant. In the following, this test will be referred to as a triaxial test with constant mean stress. In the case where the applied hydrostatic pressure is equal to the initial pre-consolidation pressure of the material, the situation will be called "normally consolidated". All the reported simulations are carried out at a confining pressure of $12 \mathrm{MPa}$, without pore pressure.

In order to perform a quantitative comparison of the two models, the parameters are adjusted as follows. The two constant parameters of the micro-mechanical are set to a friction angle $\alpha=0.055$ and an interface tensile strength $h=100 \mathrm{MPa}$. In this case, the pre-consolidation pressure is $12 \mathrm{MPa}$ for a porosity $\phi=36.5 \%$. The three constant parameters of the MCC model are then chosen such as: the pre-consolidation pressure is also $12 \mathrm{MPa}$ for a porosity of $36.5 \%$, and the critical state is reached at the same stress and porosity state as for the micro-mechanical model for the triaxial test with constant mean stress of $12 \mathrm{MPa}$ and initial porosity of $36.5 \%$ ("normally consolidated" situation). The parameter values are summarized in Tab. 1.

For both models, the material is supposed linear elastic before plasticity occurs, with the same elastic stiffness.

Three situations (or three types of samples) are then considered (see Fig. 4):

- In the "normally consolidated" situation, the initial pre-consolidation pressure of the material is equal to the applied hydrostatic pressure (12 MPa in the simulations). For both models, this corresponds to an initial porosity of $36.5 \%$ for the chosen sets of parameters.

- In the "wetter than critical" situation, the initial pre-consolidation pressure of the material is larger than the applied hydrostatic pressure and the stress path first encounters the yield surface at a stress state on the wet side of the critical state line, that is on the side leading to a decreasing porosity and thus to hardening. For both models, an initial porosity of $35.5 \%$ is an example of a "wetter than critical" situation for the chosen sets of parameters. 

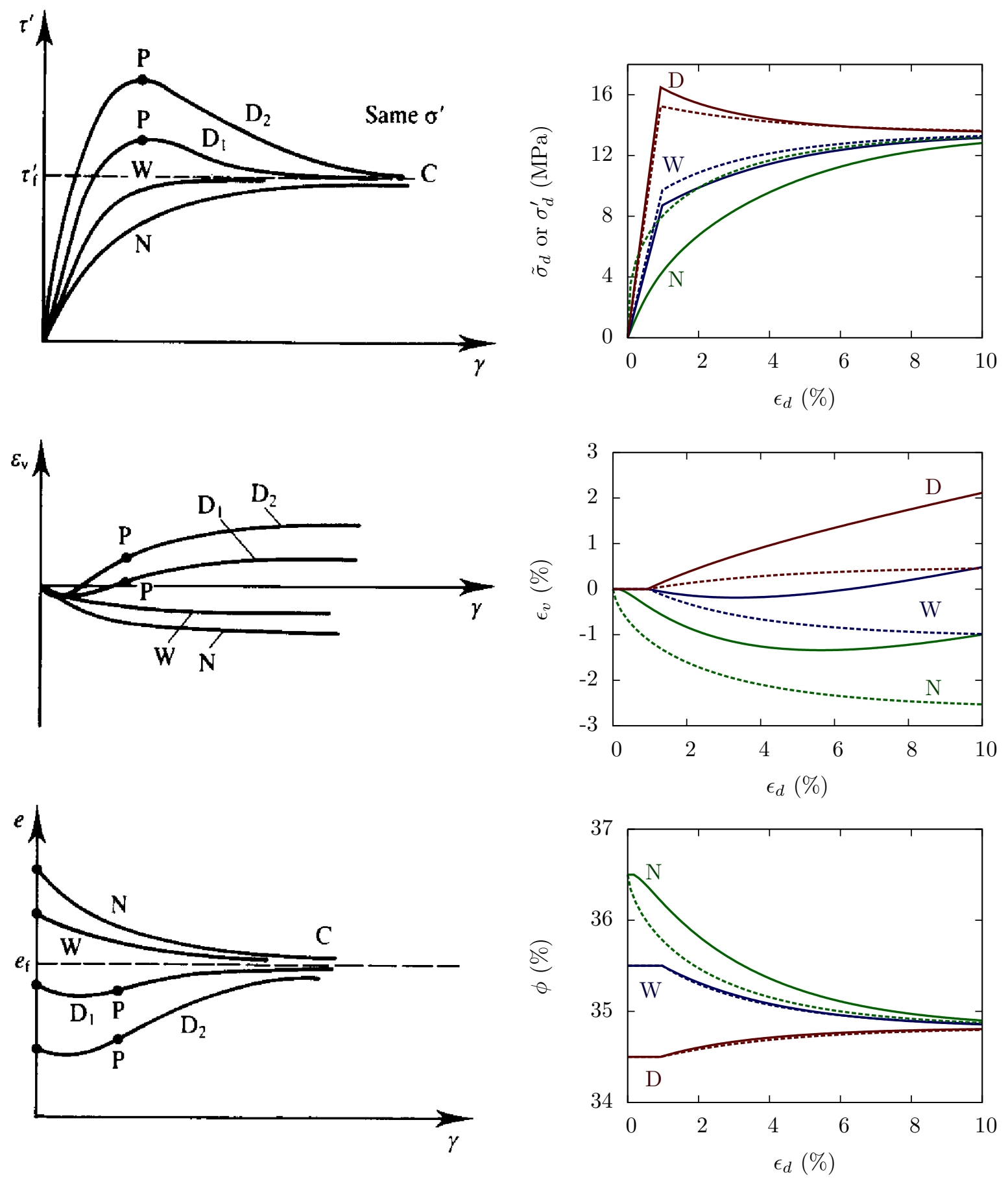

(a) experimental observations

(b) models

Figure 6: (a) From Atkinson (1993): idealized responses to drained shear test based on experimental data from Atkinson and Bransby (1978); Wood (1991). The notations are: $e=\phi /(1-\phi)=$ voids ratio, $\gamma=$ shear strain, $\epsilon_{v}=$ volumetric strain, $\tau=$ shear stress, $\sigma=$ normal stress, $\mathrm{N}=$ normally consolidated sample, $\mathrm{W}=$ "wet side of critical", $\mathrm{D}=$ "dry side of critical", $\mathrm{C}=$ critical state, $\mathrm{P}=$ peak state. (b) Elasto-plastic simulations of triaxial tests with constant mean stress using the micro-mechanical model (full line) or the modified Cam clay model (dashed line). Only the initial porosity differs in the three simulations N, W and D. 


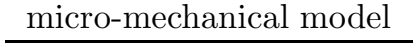

$\begin{array}{lc}h & 100 \mathrm{MPa} \\ \alpha & 0.055\end{array}$

modified Cam clay model

$\begin{array}{cc}P_{\mathrm{c}}^{0} & 12 \mathrm{MPa} \\ e^{0} & 0.575 \\ \kappa & 17.1 \\ M & 1.38\end{array}$

Table 1: Values of the parameters used in Figs. 4, 5 and 6

- In the "dryer than critical" situation, the initial pre-consolidation pressure of the material is larger than the applied hydrostatic pressure but the stress path first encounters the yield surface at a stress state on the dry side of the critical state line, that is on the side leading to an increasing porosity and thus to softening. For both models, an initial porosity of $34.5 \%$ is an example of a "dryer than critical" situation.

Using this terminology, the "normally consolidated" situation is of course a limiting case of a "wetter than critical" situation.

The results of the simulations are presented in Figs. 5 and 6. In the "normally consolidated" situation, plasticity occurs right at the onset of the deviatoric load. The components of the total strain are shown in Fig. 5. At a given stress state, the total axial and lateral strains are larger for the micro-mechanical model than for the MCC model. The volumetric strains are similar at low deviatoric stresses, but significantly differ while reaching the critical state. As expected, at the critical state, the volumetric strain rate is indeed null for the MCC model and dilatant for the micro-mechanical model. This trend is also observed for the wetter or dryer than critical situations in the simulated $\left(\epsilon_{d}, \epsilon_{v}\right)$ curves of Fig. 6. For the three tested situations, the simulated $\left(\epsilon_{d}, \sigma_{d}\right)$ and $\left(\epsilon_{d}, \phi\right)$ curves of Fig. 6 have a comparable trend for the two models. The agreement is particularly good for the wetter or dryer than critical situations.

The simulation sets are compared qualitatively on Fig. 6 to idealized response curves of clays to drained shear tests from Atkinson (1993) based on experimental observations by Atkinson and Bransby (1978); Wood (1991). Before yield, in the elastic part, the simulations are not representative of the experimentations. The sharp angle at the transition between elasticity and plasticity results from the fact the hardening due to stored elastic energy has been neglected. In other words, the step of constrained plastic flow (see section 3.1) is omitted by the present model. In the plastic part, the stress and porosity evolutions are well captured. As for the volumetric strain evolution, the MCC model better captures the experimental trends from Atkinson (1993) than the micro-mechanical model. However, the micro-mechanical model is more suited than the MCC model to describe the dilatant behavior observed at the critical state on the Tournemire shale (Masri et al., 2014) and the Callovo-Oxfordian argillite (Chiarelli et al., 2003).

\subsection{Discussion}

While the predictions of the model are satisfactory in terms of the stress-strain behavior, some limitations have been noted concerning the volumetric deformation at large deviatoric strains $(\approx 10 \%)$ in the normally consolidated case ("wetter than critical"). Indeed, at the critical state, the predicted behavior remains dilatant while experimental observations suggest that the material can be sheared without additional volumetric strain. This constitutes an important feature of the critical state model. This deviation of the micro-mechanical model with respect to the experimental data most likely goes back to the assumption of an associated flow rule at the microscopic scale.

Indeed, for frictional geomaterials obeying an associated flow rule, it is well known that the dilatant behavior strongly over-predicts the real behavior. The current practice in the phenomenological approach consists in introducing a dilatancy angle smaller than the friction angle of the yield function; this amounts to a non-associated plastic behavior. This suggests a way to improve the quantitative performance of the present micromechanical model by introducing a non-associated flow rule for the grain-to-grain interfaces 


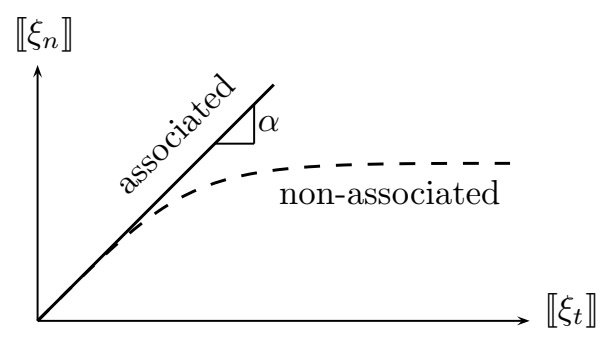

Figure 7: Proposal of a non-associated flow rule for the grain-to-grain interfaces at the microscopic scale with strain-dependant dilatancy coefficient. $\llbracket \xi_{n} \rrbracket$ and $\llbracket \xi_{t} \rrbracket$ are the normal and tangent components of the interface displacement jump $\llbracket \boldsymbol{\xi} \rrbracket$ related to the interface velocity jump by $\llbracket \dot{\boldsymbol{\xi}} \rrbracket=\llbracket \boldsymbol{v} \rrbracket$.

at the microscopic level. Indeed, the associated flow rule (4) for the interface yield function (3) assumed in this paper could be replaced by:

$$
\llbracket v_{n} \rrbracket=\beta \llbracket v_{t} \rrbracket
$$

where the dilatancy coefficient $\beta$ belongs to $[0 ; \alpha]$.

While this would certainly improve the quantitative predictions at large strain, this is not completely satisfactory. In fact, the associated rule is likely to be valid at small strain and the dilatancy coefficient should be regarded as an evolving parameter decreasing from $\alpha$ to 0 as the deviatoric strain increases. As suggested in Fig. 7, a suitable proposal of a non-associated flow rule would be such that the normal velocity jump across the interfaces were initially tangent to the associated behavior, while it would tend towards 0 at large strains. Such flow rule would be in accordance with critical state soil mechanics as is it would remove the origin of dilatancy at the critical state. It also seems physically more sound as the dilatancy of the frictional interfaces, due to the roughness of the surfaces at a lower scale, is expected to produce normal displacement jumps no greater than the size of the asperities even for large tangential displacement jumps.

However, if we restrict to small deviatoric strains, a good agreement with experimental data of a triaxial test on a Callovo-Oxfordian argillite has been obtained. Its is recalled that the argillite can be viewed as a matrix-inclusion composite in which clay plays the role of the matrix, embedding calcite and quartz inclusions. A 3-scale model presented in Bignonnet (2014) and not detailed herein, based on the present model for the clay matrix but also comprising the effect of a larger scale through the strength model presented in Bignonnet et al. (2015), yields the simulation presented in Fig. 8. The transition from a contractant to dilatant behavior is well reproduced by the model. In this specific case, the agreement can be traced back to the fact that the range of deviatoric strain is small enough $(\leq 2 \%)$ for the associated flow rule of the interface to be a good approximation of the behavior.

\section{Conclusion}

A purely micro-mechanical model for the plasticity of granular materials with hardening due to porosity changes has been proposed. The plasticity model is based on a re-interpretation of the micro-mechanical strength model for cohesive frictional granular media by He et al. (2013). The hardening law by porosity changes is explicitly expressed by localization of the failure mechanism used in the homogenization process, and does not require any phenomenological hardening law. Furthermore, it has been proved that the porosity change law can also be directly obtained at the macroscopic scale by the normal flow rule in the framework of poro-plasticity.

The micro-mechanical plasticity model is analytical and fully explicit. It depends only on two constant material parameters with a clear physical signification at the microscopic scale: the friction angle and the tensile strength of the grain to grain interfaces. The main features of critical state soil mechanics have been 


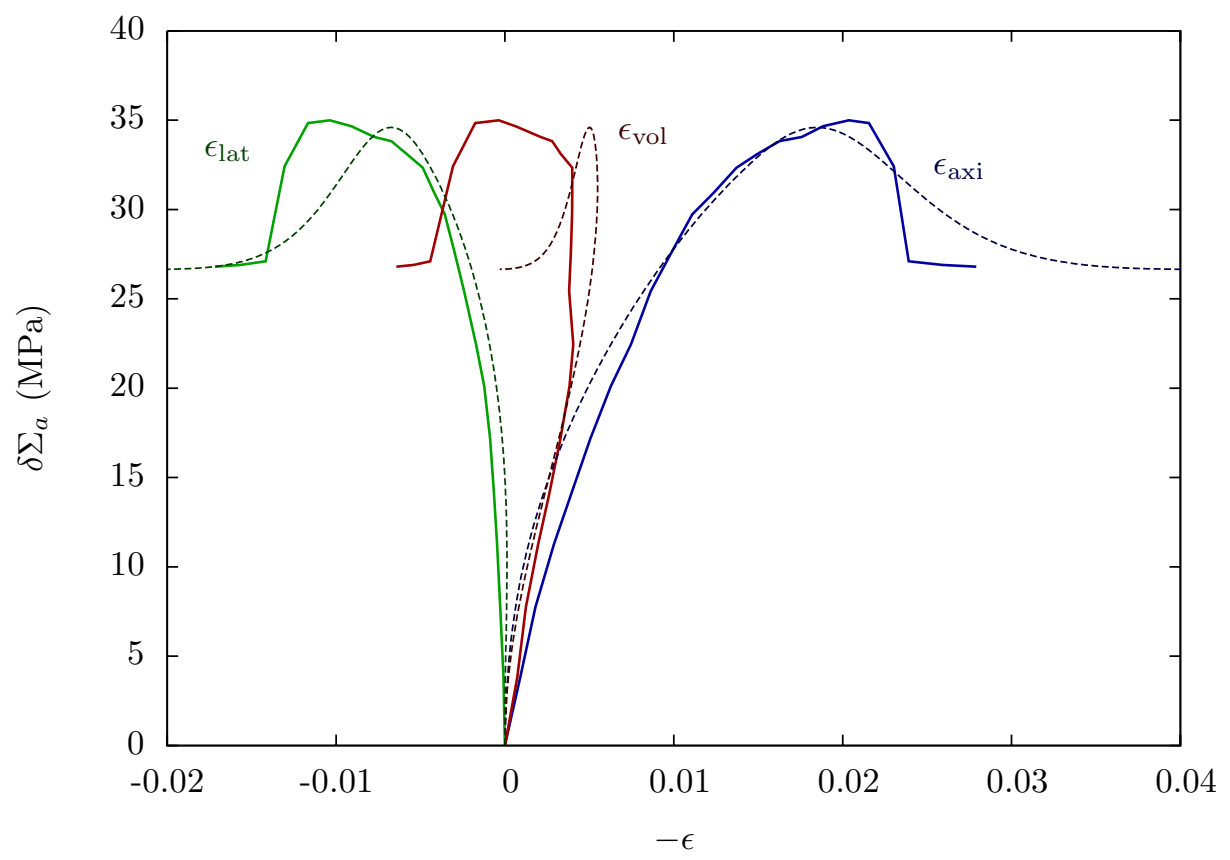

Figure 8: Axial, lateral and volumetric strains in a triaxial test on a Callovo-Oxfordian argillite with mean stress kept equal to $12 \mathrm{MPa}$ while the differential axial stress $\delta \Sigma_{a}$ is increased. Full line : experimental results, dotted line : simulation using a 3-scale plasticity model (see Bignonnet (2014)) based on the present micro-mechanical model for the clay matrix with $\alpha=0.055$ and $h=93 \mathrm{MPa}$ embedding $60 \%$ of rigid inclusions. Experimental data courtesy of ANDRA. 
retrieved: critical state line, state boundary surface in the stress/porosity space, hardening or softening due to change in porosity and ability to describe both dilatancy and contractancy.

It cannot be enough emphasized that the proposed model, although based on micro-mechanics for its elaboration, can be readily used at the macroscopic scale by engineers just as any other empirical model could be. However, the present model relies on simplifying assumptions at the microscopic scale. In order to be predictive, depending on the actual material, these assumptions may have to be refined based on experimental evidences at the macroscopic scale.

As a matter of fact, the micro-mechanical model is very similar to the phenomenological modified Cam clay model as discussed in section 4.1 and can be used in a similar fashion. The main differences between the two models are the dilatancy or not of the plastic flow at the critical state, and the restricted porosities interval for the micro-mechanical model.

Proposed perspectives to this work are to take into account the reinforcement of the clay matrix by inclusions in shales and argillite. The plasticity of these 3 -scale materials will be investigated using the strength model by Bignonnet et al. (2015). Another perspective would be to consider intra-granular mechanisms at the microscopic scale in addition to the hereby used inter-granular (interfacial) mechanism, in order to deal with low-porosity granular materials. Furthermore, future works should be dedicated to the implementation of an evolving non-associated plastic flow rule at the grain-to-grain interfaces at the microscopic scale, in order to reproduce the absence of volumetric deformation at the critical state, at large strains.

\section{Acknowledgements}

The authors acknowledge the support of the french agency for nuclear waste storage ANDRA.

\section{References}

Ami Saada, R., Bonnet, G., Bouvard, D., 1996. Thermomechanical behavior of casting sands: experiments and elastoplastic modeling. Int. J. Plasticity 12, 273-294.

Atkinson, J.H., 1993. The Mechanics of Soils and Foundations. McGraw-Hill, London.

Atkinson, J.H., Bransby, P.L., 1978. The Mechanics of Soils. McGraw-Hill, London.

Barthélémy, J.F., 2005. Approche micromécanique de la rupture et de la fissuration dans les géomatériaux. Ph.D. thesis. Ecole Nationale des Ponts et Chaussées.

Barthélémy, J.F., Dormieux, L., 2004. A micromechanical approach to the strength criterion of drucker-prager materials reinforced by rigid inclusions. International Journal for Numerical and Analytical Methods in Geomechanics 28, 565-582.

Barthélémy, J.F., Dormieux, L., Maghous, S., 2003. Micromechanical approach to the modelling of compaction at large strains. Computers and Geotechnics 30, 321-338.

Bignonnet, F., 2014. Caractérisation expérimentale et modélisation micromécanique de la perméabilité et de la résistance de roches argileuses. Ph.D. thesis. Université Paris Est.

Bignonnet, F., Dormieux, L., Lemarchand, E., 2015. Strength of a matrix with elliptic criterion reinforced by rigid inclusions with imperfect interfaces. Eur. J. Mech. A/Solids doi:10.1016/j.euromechsol.2015.02.003.

de Buhan, P., Dormieux, L., 1996. On the validity of the effective stress concept for assessing the strength of saturated porous materials: a homogenization approach. J. Mech. Phys. Solids 44, 1649-1667.

Chiarelli, A., Shao, J., Hoteit, N., 2003. Modeling of elastoplastic damage behavior of a claystone. Int. J. Plasticity 19 , 23-45.

Collard, C., Favier, V., Berbenni, S., Berveiller, M., 2010. Role of discrete intra-granular slip bands on the strain-hardening of polycrystals. Int. J. Plasticity 26, 310-328.

Coussy, O., 1991. Mécanique des milieux poreux. Éditions Technip.

Dormieux, L., Jeannin, L., Bemer, E., Le, T.H., Sanahuja, J., 2010. Micromechanical models of the strength of a sandstone. International Journal for Numerical and Analytical Methods in Geomechanics 34, 249-271.

Dormieux, L., Sanahuja, J., Maalej, Y., 2007. Résistance d'un polycristal avec interfaces intergranulaires imparfaites. Comptes Rendus de Mecanique 335, 25-31.

Guo, T.F., Faleskog, J., Shih, C., 2008. Continuum modeling of a porous solid with pressure-sensitive dilatant matrix. J. Mech. Phys. Solids 56, 2188-2212.

Gurson, A., 1977. Continuum theory of ductile rupture by void nucleation and growth. Part I: Yield criteria and flow rules for porous ductile media. J. Engng. Matl. Tech. Trans. ASME 99, 2-15.

Hashin, Z., 1991. The spherical inclusion with imperfect interface. Journal of Applied Mechanics 58, $444-449$.

He, Z., Dormieux, L., Lemarchand, E., Kondo, D., 2013. Cohesive mohr-coulomb interface effects on the strength criterion of materials with granular-based microstructure. European Journal of Mechanics A/Solids 42, 430-440.

Maalej, Y., Dormieux, L., Sanahuja, J., 2007. Elastic nonlinear behaviour of a granular medium: micromechanical approach. Comptes Rendus Mécanique 8, 461-466. 
Maalej, Y., Dormieux, L., Sanahuja, J., 2009. Micromechanical approach to the failure criterion of granular media. European Journal of Mechanics A/Solids 28, 647-653.

Maghous, S., Dormieux, L., Barthélémy, J.F., 2009. Micromechanical approach to the strength properties of frictional geomaterials. European Journal of Mechanics A/Solids 28, 179-188.

Masri, M., Sibai, M., Shao, J., Mainguy, M., 2014. Experimental investigation of the effect of temperature on the mechanical behavior of tournemire shale. Int. J. Rock Mech. Mining Sci. 70, 185-191.

Nadah, J., Bignonnet, F., Davy, C.A., Skoczylas, F., Troadec, D., Bakowski, S., 2013. Microstructure and poro-mechanical performance of haubourdin chalk. International Journal of Rock Mechanics \& Mining Sciences 58, $149-165$.

Nguyen, L.D., Fatahi, B., Khabbaz, H., 2014. A constitutive model for cemented clays capturing cementation degradation. Int. J. Plasticity 56, 1-18.

Nicot, F., Darve, F., RNVO Group: Natural Hazards and Vulnerability of Structures, 2005. A multi-scale approach to granular materials. Mech. Mat. 37, 980-1006.

Perić, D., Ayari, M.A., 2002a. Influence of lode's angle on the pore pressure generation in soils. Int. J. Plasticity $18,1039-1059$.

Perić, D., Ayari, M.A., 2002b. On the analytical solutions for the three-invariant cam clay model. Int. J. Plasticity 18, 1061-1082.

Roscoe, K.H., Burland, J.B., 1968. On the generalized stress-strain behavior of "wet" clay, in: Heyman, J., Leckie, F.A. (Eds.), Engineering plasticity, Cambridge University Press, Cambridge. pp. 535-609.

Schofield, A., Wroth, P., 1968. Critical State Soil Mechanics. McGraw-Hill.

Scholtès, L., Hicher, P.Y., Sibille, L., 2010. Multiscale approaches to describe mechanical responses induced by particle removal in granular materials. C. R. Mecanique 338, 627-638.

Shen, W., Dormieux, L., Kondo, D., Shao, J., 2012. A closed-form three scale model for ductile rocks with a plastically compressible porous matrix. Mech. Mater. 59, 73-86.

Sibille, L., Hadda, N., Nicot, F., Tordesillas, A., Darve, F., 2015. Granular plasticity, a contribution from discrete mechanics. J. Mech. Phys. Solids 75, 119-136.

Song, Y., Davy, C.A., Troadec, D., Blanchenet, A.M., Skoczylas, F., Talandier, J., Robinet, J., 2015. Fine multi-scale pore structure of cox claystone: towards the prediction of fluid transport. Submitted to Marine and Petroleum Engineering .

Steinhauser, M.O., Grass, K., 2005. Failure and plasticity models of ceramics, a numerical study, in: Khan, A.S., Kohei, A.R. (Eds.), Dislocations, Plasticity, Damage and Metal Forming : Materials Response and Multiscale Modeling, The 11th Int. Symposium on Plasticity and Current Applications, Kauai, Hawaii. Proceedings. Neat Press.

Suebsuk, J., Horpibulsuk, S., Liu, M.D., 2010. Modified structured cam clay: A generalised critical state model for destructured, naturally structured and artificially structured clays. Computers and Geotechnics 37, 956-968.

Suquet, P., 1995. Overall properties of nonlinear composites: a modified secant moduli approach and its link with PonteCastaneda's nonlinear variational procedure. C. R. Acad. Sci. Paris 320, 563-571.

Suquet, P., 1997. Effective behavior of nonlinear composites, in: Continuum Micromechanics. Springer-Verlag.

Wood, D.M., 1991. Soil Behaviour and Critical State Soil Mechanics. Cambridge University Press, Cambridge.

Xie, S., Shao, J., 2006. Elastoplastic deformation of a porous rock and water interaction. Int. J. Plasticity $22,2195-2225$.

Xie, S., Shao, J., 2012. Experimental investigation and poroplastic modelling of saturated porous geomaterials. Int. J. Plasticity $39,27-45$.

Xie, S., Shao, J.F., 2015. An Experimental Study and Constitutive Modeling of Saturated Porous Rocks. Rock Mech. Rock Eng. 48, 223-234.

Zhu, Q., Shao, J., Mainguy, M., 2010. A micromechanics-based elastoplastic damage model for granular materials at low confining pressure. Int. J. Plasticity 26, 586-602. 